\title{
EFFECTS OF THIOURACIL COMPOUNDS ON CHEMICALLY INDUCED RAT MAMMARY GLAND CARCINOGENESIS
}

\author{
Dana MACEJOVÁ1, Slavomíra ONDKOVÁ1, Ján LíŠKA1,2, Július BRTKO1
}

${ }^{1}$ Institute of Experimental Endocrinology, SAS, Vlárska 3, 83306 Bratislava, Slovakia

2 Institute of Histology and Embryology, Medical Faculty of Comenius University, Sasinkova 4, 81108 Bratislava, Slovakia

Thyroidal status can play important role in progression mammary gland tumour growth. We have already shown that hypothyroidism induced by application of 6-npropylthiouracil (PTU) - inhibitor of type I iodothyronine 5'deiodinase $\left(5^{\prime} \mathrm{DI}\right)$ - prolonged tumour latency and reduced number, volume and burden of 1-methyl-1-nitrosourea (MNU) induced rat mammary gland tumours in SpragueDawley female rats (Macejova et al., 2005). 4-hydroxy-2mercapto-6-methylpyrimidine (MTU) is a derivative of PTU, thus the effects of PTU or MTU on tumour progression as well as expression of selected nuclear receptors in MNU-induced mammary gland tumours and rat livers were investigated in this experiment.

Tumours
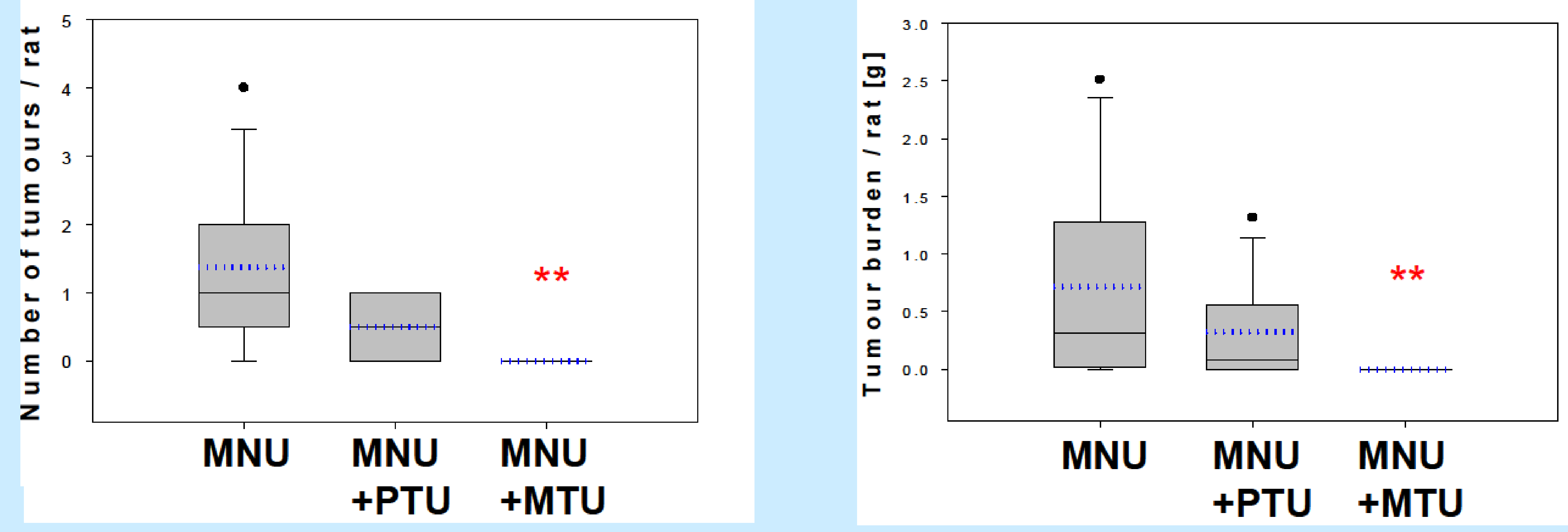

lodothyronine 5'-deiodinase activity in liver

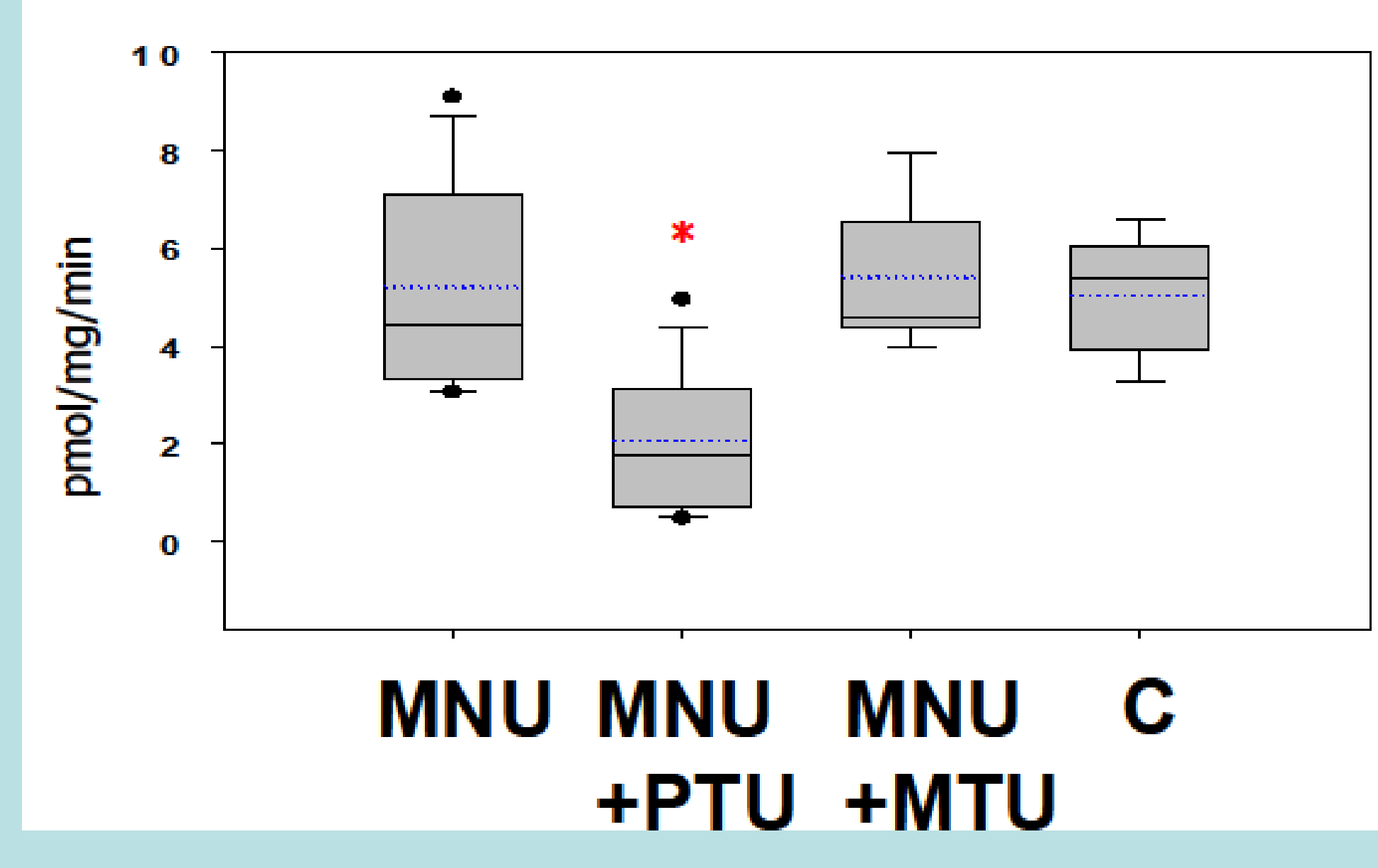

Results are expressed as median (range 5$95 \%)$ or mean SD

${ }^{*} p<0.05 ;{ }^{* *} p<0.01 ;{ }^{* * *} p<0.001$ vs. MNU $+p<0.05 ;++p ? 0.01 ;+++p<0.001$ vs. $C$

\section{Experimental design:}

Female Sprague-Dawley rats were given $50 \mathrm{mg} / \mathrm{kg}$ MNU i.p. on $62^{\text {nd }}, 109^{\text {th }}$ and $150^{\text {th }}$ day of age. From $56^{\text {th }}$ day of age, the PTU group of MNU treated rats was recieving PTU (1 mg/kg) 3x per week and MTU group of MNU animals $0.1 \% \mathrm{w} / \mathrm{v}$ of MTU in drinking water untill the end of experiment.

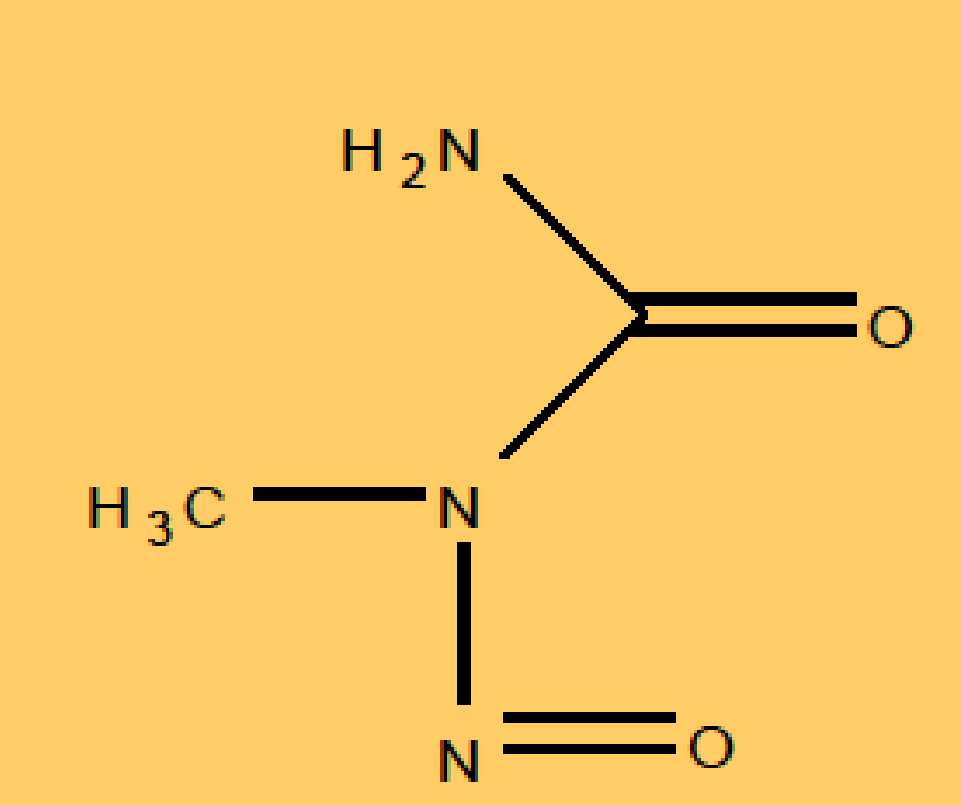<smiles>CCCc1cc(=O)[nH]c(=S)[nH]1</smiles><smiles>Cc1cc(O)nc(S)n1</smiles>

$N$-methyl- $N$-nitrosourea (MNU) 4-hydroxy-2-mercapto-6 methylpyrimidine (MTU)
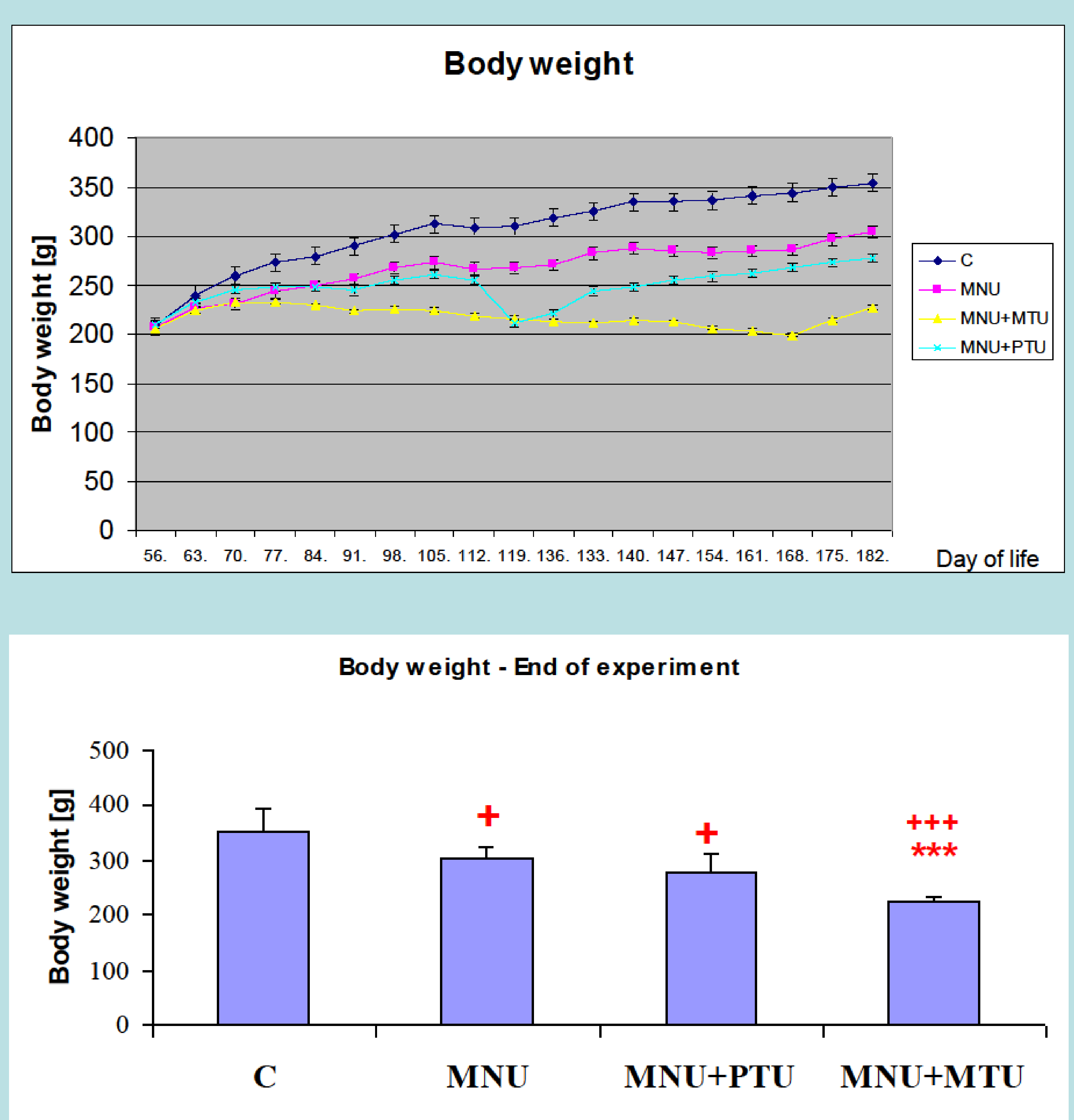

Tumours - EMSA
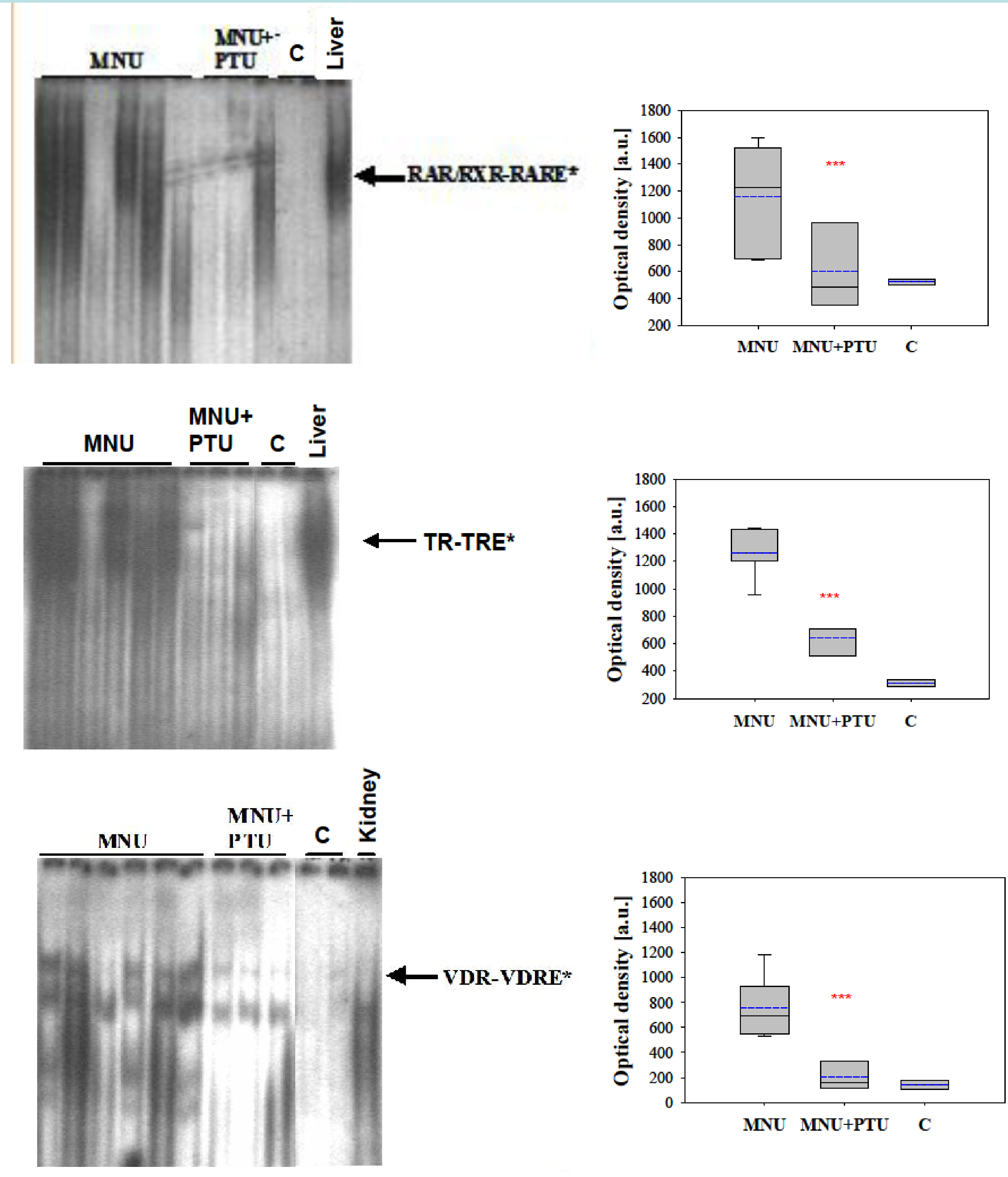

Liver - RT-PCR
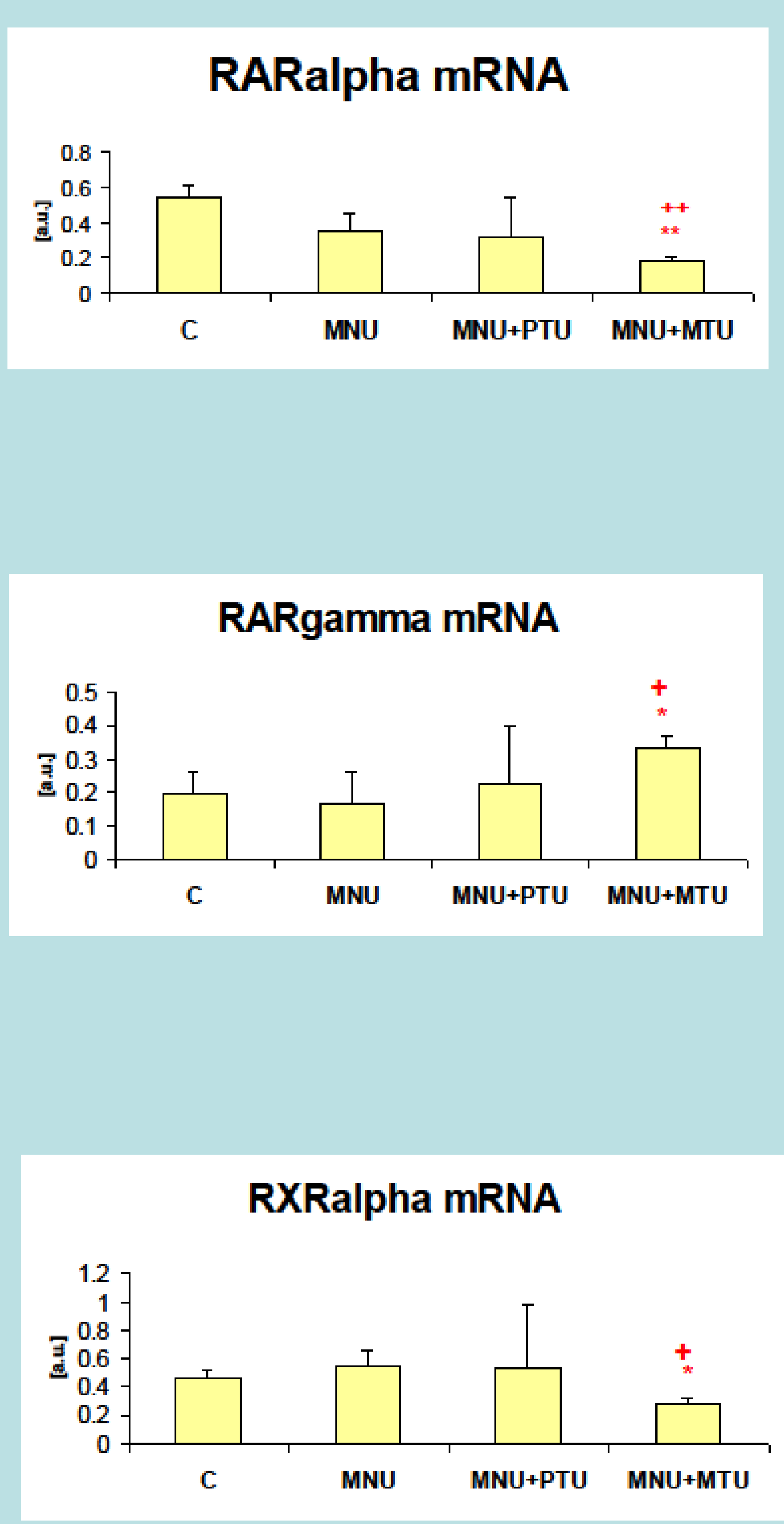

Conclusion

Administration of PTU to MNU treated animals markedly reduced number of tumours when compared to MNU group of animals. Furthermore, we did not find any tumour in the MTU group of animals. However we have detected significantly reduced body weight when compared to PTU, untreated MNU animals and healthy control animals. Administration of MTU resulted in reduced expression of RARalpha, RXRalpha and increased expression of RARgamma in rat liver (vs. MNU and C). Using EMSA method, we have found significantly reduced amount of nuclear receptor-hormone responsive elements (RARE, TRE, VDRE) complex in tumours of PTU treated animals (vs. MNU animals). Since MTU did not affect 5'DI in the liver, the mechanism of MTU action needs further investigation.

\section{References}

[1] Macejova et al., (2005) Mol. Cell. Endocrinol. 244(1-2):47-56 